\title{
Contact with HIV prevention services highest in gay and bisexual men at greatest risk: cross-sectional survey in Scotland
}

\author{
Lisa M McDaid ${ }^{1 *}$, Graham J Hart ${ }^{2}$
}

\begin{abstract}
Background: Men who have sex with men (MSM) remain the group most at risk of acquiring HIV in the UK and new HIV prevention strategies are needed. In this paper, we examine what contact MSM currently have with HIV prevention activities and assess the extent to which these could be utilised further.

Methods: Anonymous, self-complete questionnaires and Orasure ${ }^{T M}$ oral fluid collection kits were distributed to men visiting the commercial gay scenes in Glasgow and Edinburgh in April/May 2008. 1508 men completed questionnaires (70.5\% response rate) and 1277 provided oral fluid samples (59.7\% response rate); 1318 men were eligible for inclusion in the analyses.

Results: $82.5 \%$ reported some contact with HIV prevention activities in the past 12 months, $73.1 \%$ obtained free condoms from a gay venue or the Internet, $51.1 \%$ reported accessing sexual health information (from either leaflets in gay venues or via the Internet), $13.5 \%$ reported talking to an outreach worker and $8.0 \%$ reported participating in counselling on sexual health or HIV prevention. Contact with HIV prevention activities was associated with frequency of gay scene use and either HIV or other STI testing in the past 12 months, but not with sexual risk behaviours. Utilising counselling was also more likely among men who reported having had an STI in the past 12 months and HIV-positive men.

Conclusions: Men at highest risk, and those likely to be in contact with sexual health services, are those who report most contact with a range of current HIV prevention activities. Offering combination prevention, including outreach by peer health workers, increased uptake of sexual health services delivering behavioural and biomedical interventions, and supported by social marketing to ensure continued community engagement and support, could be the way forward. Focused investment in the needs of those at highest risk, including those diagnosed HIVpositive, may generate a prevention dividend in the long term.
\end{abstract}

\section{Background}

Men who have sex with men (MSM) remain the group most at risk of acquiring HIV in the UK, accounting for $38 \%$ of diagnoses in $2008,83 \%$ of which were probably acquired in the UK [1]. New HIV prevention strategies are needed and current policy initiatives set prevention as key to efforts to combat the HIV epidemic among MSM $[1,2]$.

Combination prevention, which incorporates biomedical and behavioural, as well as social and structural,

\footnotetext{
* Correspondence: lisa@sphsu.mrc.ac.uk

1 MRC/CSO Social and Public Health Sciences Unit, 4 Lilybank Gardens,

Glasgow, G12 8RZ, UK

Full list of author information is available at the end of the article
}

interventions has been argued as the way forward [3]. Furthermore, early, successful HIV prevention among MSM has been credited to the collective response of gay communities and their widespread adoption of safer sex behaviours, leading to calls for a renewed community response [4]. However, recent research has highlighted the evolving nature of the 'gay community' and its changing role in HIV prevention [5-7]; the divergence of different gay communities, and particularly ambivalence and changing community norms around safer sex [6]; the individualization of risk practices and responsibilities [5]; and structural, environmental and other physical changes in gay communities [7]. As such, the community's role in HIV prevention has changed and it has

\section{() Biomed Central}


been argued that community-level prevention efforts have been difficult to maintain over the course of the epidemic as the threat of HIV has diminished, questioning the likelihood and potential of a renewed community response [8]. While further research is required to explore the meaning of 'gay community' to MSM in the UK, there is also a need to examine what contact MSM currently have with HIV prevention activities and to assess the extent to which these could be utilised in new prevention efforts.

Since 1996, we have surveyed the HIV-related sexual behaviour of MSM in Scotland [9-17]. This paper examines the extent to which MSM engage with existing HIV prevention activities, the factors associated with this, and discusses the opportunities presented for further intervention efforts.

\section{Methods}

The 2008 MRC Gay Men's Survey collected anonymous, self-complete questionnaires and (Orasure ${ }^{\mathrm{TM}}$ ) oral fluid specimens. Representative samples were recruited from commercial gay venues (12 bars and 2 saunas) in Glasgow and Edinburgh, Scotland's two largest cities, using time and location sampling [15]. 1514 men participated in the survey $(70.8 \%$ response rate [RR]); 1508 completed questionnaires (70.5\% RR) and 1277 provided oral fluid samples (59.7\% RR). Of the 1508 men who completed questionnaires, 54 (3.6\%) heterosexual men reported no sexual contact with men in the previous 12 months and are excluded from the sample.

1318 men provided data on the current HIV prevention variables and 136 men with missing data on any of these are excluded from the analyses in this paper. When compared in multivariate analysis, men who provided data on the HIV prevention variables had lower odds of being surveyed in Glasgow (AOR $=0.52,95 \%$ CI 0.33-0.81), being surveyed in a sauna $(\mathrm{AOR}=0.43$, 95\% CI 0.22-0.85), and of having had an STI in the past 12 months $($ AOR $=0.46,95 \%$ CI 0.25-0.79) than men with missing data on these variables.

Questionnaires included demographics, HIV testing history and sexual risk behaviour in the past 12 months [Additional file 1]. Participants were asked if they had, in the past 12 months, picked up sexual health leaflets in bars, clubs or saunas; looked for safer sex/sexual health information on the Internet; obtained free condoms from bars, clubs, saunas or the Internet; talked to an outreach worker in a bar, club or sauna; or participated in one to one or group counselling sessions on sexual health or HIV prevention.

Oral fluid specimens were analysed at the West of Scotland Specialist Virology Centre (screened for antiHIV using an enzyme immunoassay; positives rescreened, and repeat reactives confirmed using Western
Blot). Data were analysed with SPSS 15.0. Logistic regression was used to estimate odds ratios and 95\% confidence intervals (CI). Ethical approval was granted by University of Glasgow, Faculty of Medicine Ethics Committee.

\section{Results}

\section{Sample Characteristics}

Sample characteristics are shown in Table 1. The majority were surveyed in bars and identified as gay. The majority were aged over 26 years; $76.8 \%$ lived in the Glasgow or Edinburgh areas. Only 3.3\% reported being from minority ethnic groups. Just less than half reported degree or post-graduate education and the majority were employed. Many respondents $(46.8 \%)$ visited the gay scene at least once a week. Just under half had been tested for HIV or other sexually transmitted infections (STIs) in the past 12 months; 3.5\% had a HIV-positive oral fluid sample. Most men (96.2\%) reported some sexual contact in the past 12 months, $12.4 \%$ reported UAI with $2+$ partners, $20.5 \%$ reported UAI with casual partners, $24.9 \%$ reported UAI with partners of unknown/discordant HIV status, and $8.3 \%$ had had an STI in the past 12 months (Table 1 ).

\section{Contact with HIV prevention activities}

Overall, 1135 men (82.5\%) reported some contact with HIV prevention activities in the past 12 months (Table 2). Having obtained free condoms from a gay venue or the Internet was the most frequently reported HIV prevention activity (73.1\%), but over a third of men also reported picking up sexual health leaflets in gay venues or using the Internet to look for safer sex or sexual health information. Overall, 674 men (51.1\%) reported accessing sexual health information (from either leaflets in bars, clubs or saunas, or via the Internet). Only $13.5 \%$ reported talking to an outreach worker and only $8.0 \%$ reported participating in one to one or group counselling on sexual health or HIV prevention. Only 47 men (3.6\%) reported use of all four HIV prevention activities.

\section{Factors associated with contact with HIV prevention activities}

Table 3 shows the factors associated with contact with HIV prevention activities. The likelihood of engaging with all of the listed HIV prevention activities was higher among men who were more frequent scene users, men who had had an HIV, or other STI, test in the past 12 months, men who reported 10 or more sexual partners in the past 12 months, and men who reported having had an STI in the past 12 months (it should be noted that some STIs can be transmitted during lower risk sexual practices so are not necessarily 
Table 1 Sample characteristics $(\mathbf{N}=1318)$

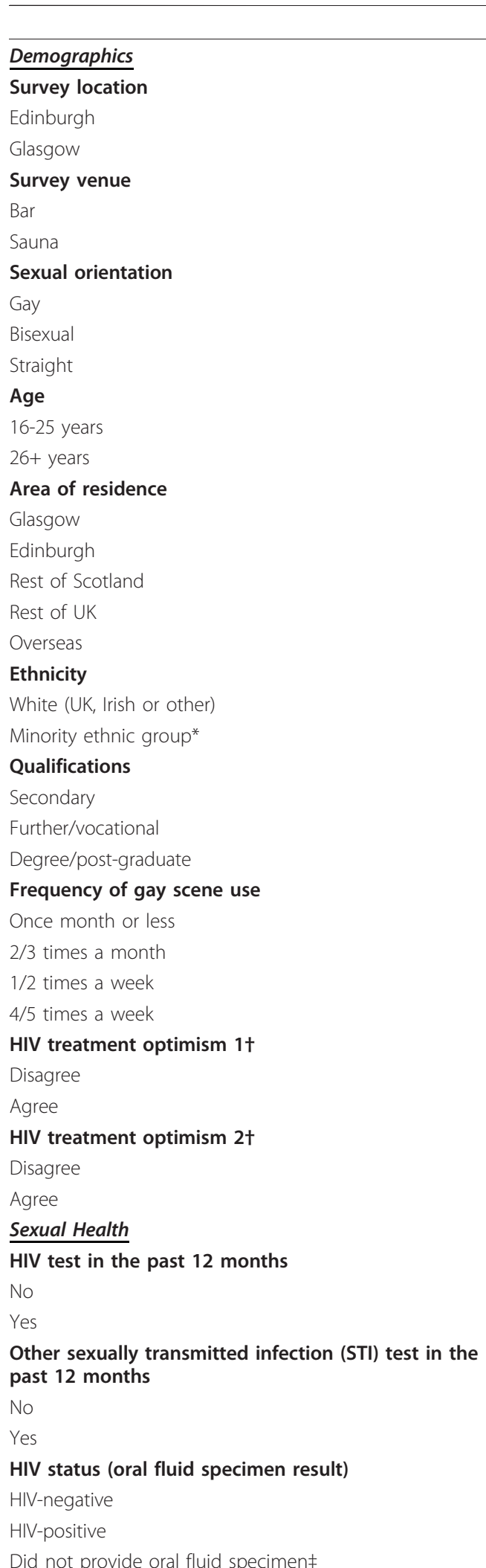

Table 1 Sample characteristics $(\mathbf{N}=1318)$ (Continued)

n $\%$

$559 \quad 42.2$

$759 \quad 57.6$

124394.3

$75 \quad 5.7$

118090.1

1138.6

$17 \quad 1.3$

$378 \quad 29.0$

$926 \quad 71.0$

$538 \quad 41.9$

$449 \quad 34.9$

$204 \quad 15.9$

$67 \quad 5.2$

$27 \quad 2$.

127296.7

$44 \quad 3.3$

$195 \quad 15.9$

$460 \quad 37.5$

$571 \quad 46.6$

$327 \quad 25.5$

$354 \quad 27.7$

$432 \quad 33.8$

$167 \quad 13.0$

$938 \quad 74.2$

$327 \quad 25.8$

105683.5

$209 \quad 16.5$

$667 \quad 51.9$

61848.1

71154.3

$599 \quad 45.7$

107781.9

$46 \quad 3.5$

$192 \quad 14.6$

\section{Sexual Risk Behaviour in the past 12 months}

Number of sexual partners

Less than 10

$927 \quad 72.7$

10 or more

$348 \quad 27.3$

Number of anal sex partners

Less than 10

112689.3

10 or more

$135 \quad 10.7$

Number of unprotected anal intercourse (UAI) partners

0/1 partner

112787.6

2 or more partners

$160 \quad 12.4$

UAI with casual partners

No

102379.5

Yes

UAI with partners of unknown/discordant HIV status

No

Yes

STI

No

Yes

1098.3

*Black African, Black Caribbean, Indian, Pakistani, Chinese, Arab, Latin American \& Other/Mixed.

† HIV treatment optimism 1 - 'I am less worried about HIV infection now that treatments have improved', HIV treatment optimism 2 - 'I believe that new drug therapies make people with HIV less infectious'.

₹ An additional 4 samples were not returned from the laboratory.

exclusively indicators of high risk behaviour). The likelihood of obtaining free condoms was lower among men who identified as straight, who were aged $26+$ years or who resided in areas of the UK other than Scotland. The likelihood of accessing sexual health information via gay venues or the Internet (which were combined for these analyses) was higher among men surveyed in saunas, men from minority ethnic groups, men with further and higher educational qualifications, but lower among men who did not provide oral fluid samples. The likelihood of talking to an outreach worker was lower among men aged $26+$ years and men who lived in the rest of Scotland (compared with Glasgow). The likelihood of participating in one to one or group counselling was higher among men who agreed with the HIV treatment optimism statement, 'I believe that new drug therapies make people with HIV less infectious'. The likelihood of accessing sexual health information or participating in counselling was higher among HIV-positive than HIV-negative men, but there were no differences in the proportions reporting obtaining free condoms or talking to an outreach worker, or between diagnosed and undiagnosed HIV-positive men. Almost exclusively, the likelihood of contact with HIV prevention activities was higher among men who reported more sexual partners and any of the sexual risk behaviours. A notable exception was UAI with partners of unknown/ 


\begin{tabular}{|c|c|c|c|c|}
\hline & \multicolumn{4}{|c|}{ Contact in past 12 months } \\
\hline & \multicolumn{2}{|c|}{ Yes } & \multicolumn{2}{|c|}{ No } \\
\hline & $\mathrm{n}$ & $\%$ & $\mathrm{n}$ & $\%$ \\
\hline \multicolumn{5}{|l|}{ Contact with HIV prevention activities in last 12 months } \\
\hline Any & 1082 & 82.1 & 236 & 17.9 \\
\hline Obtained free condoms from a bar/club/sauna or the Internet & 964 & 73.1 & 354 & 26.9 \\
\hline Picked up sexual health leaflet in a bar/club/sauna & 508 & 38.6 & 810 & 61.5 \\
\hline Looked for safer sex/sexual health information on the Internet & 459 & 34.8 & 859 & 65.2 \\
\hline Talked to an outreach worker in a bar/club/sauna & 178 & 13.5 & 1140 & 86.5 \\
\hline Participated in one to one or group counselling on sexual health or HIV prevention & 105 & 8.0 & 1213 & 92.0 \\
\hline
\end{tabular}

discordant HIV status, which was not associated with any HIV prevention activities.

Factors significant at the bivariate level were entered into a multivariate model for each of the HIV prevention activities (Table 4). The factors that remained significantly associated with obtaining free condoms were: age, frequency of gay scene use, STI testing in the past 12 months, and having 10 or more sexual partners in the past 12 months. The factors associated with accessing sexual health information were ethnicity and frequency of gay scene use, while odds remained lower among men who did not provide oral fluid specimens. Factors associated with talking to an outreach worker were frequency of gay scene use, and HIV and STI testing. Factors associated with participating in counselling were frequency of gay scene use, HIV treatment optimism, HIV testing, HIV-positive status and having had an STI in the past 12 months.

\section{Discussion}

In a study of the economic implications of HIV infection in the UK, it has been estimated that the lifetime HIV-related costs for diagnosed HIV-positive individuals is between $£ 280,000$ and $£ 360,000$ and preventing the HIV infections acquired and diagnosed in the UK in 2008 would save $£ 1.1$ billion in future HIV-related costs [1]. MSM, who accounted for over a third of diagnoses in 2008, most of which were probably acquired in the UK [1], are therefore a high priority for HIV prevention interventions. This is the first UK paper to report engagement with HIV prevention strategies in MSM since the advent of antiretroviral treatment in 1996.

The majority of the MSM in our community-based surveys reported having contact with HIV prevention activities in the past 12 months. Obtaining free condoms was reported by almost three quarters of the sample. Half also reported picking up sexual health leaflets in a bar, club or sauna or looking for safer sex or sexual health information on the Internet. Talking to outreach workers in gay venues or participating in one to one or group counselling on sexual health or HIV prevention was less common, reported by just one in ten respectively. Comparable data are not available elsewhere in the UK, but our findings are similar to those of the US National HIV Behavioural Surveillance survey of MSM, which found $80 \%$ had received free condoms, but few had participated in individual or group HIV prevention interventions in the past 12 months (15\% and $8 \%$, respectively) [18].

In multivariate analysis, each of the HIV prevention activities remained associated with frequency of gay scene use, but not with sexual risk behaviours (with the exception of having ten or more sexual partners, which itself only remained associated with obtaining free condoms). Frequency of gay scene use could be taken as a proxy for risk behaviour and the two were correlated, but there were no significant interactions between the two in any of the multivariate HIV prevention models and when separate models were fitted for each of the correlated variables and compared with the final models to check for the effects of collinearity, no substantively important differences were observed (data not shown). It is also of particular note that contact with HIV prevention activities (with the exception of accessing sexual health information) remained associated with either HIV or other STI testing in the past 12 months, with utilising counselling also more likely among men who reported having had an STI in the past 12 months and HIV-positive men.

There are some limitations to note when considering these results. Only men who visited the venues surveyed had the opportunity to participate and caution should be taken when generalising to a wider population of gay men. The data are cross-sectional and participants were only asked if they had contact with a pre-determined list of HIV prevention activities, not the extent of this contact, the quality, intensity, or frequency of exposure to these activities, or what, if any, impact it had on them. Other activities could have been available to, and utilised by, the men who participated in this survey. It is recognised that these factors should be assessed in the future to accurately assess the potential of prevention 


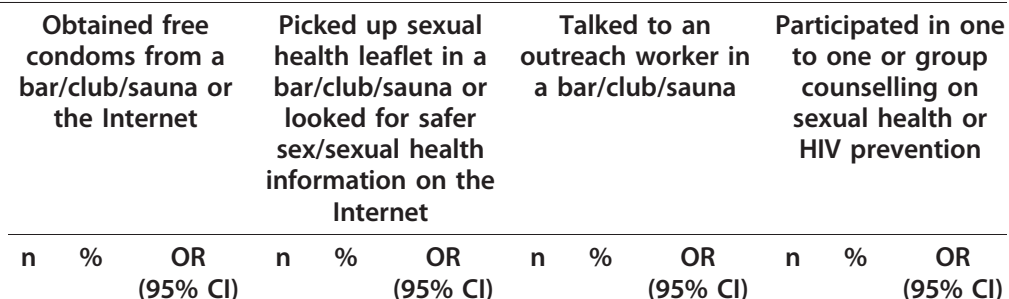

\section{Sample characteristics}

Survey location

Edinburgh

$\begin{array}{cccccccccccc}414 & 74.1 & 1 & 296 & 53.0 & 1 & 73 & 13.1 & 1 & 47 & 8.4 & 1 \\ 550 & 72.5 & 0.92 & 378 & 49.8 & 0.88 & 105 & 13.8 & 1.07 & 58 & 7.6 & 0.90 \\ & & (0.72- & & & (0.71- & & & (0.78- & & & (0.60- \\ & & 1.18) & & & 1.10) & & & 1.47) & & & 1.35)\end{array}$

Survey venue

Bar

Sauna

$$
\begin{array}{ccc}
910 & 73.2 & 1 \\
54 & 72.0 & 0.94 \\
& & (0.56- \\
& & 1.58)
\end{array}
$$

$627 \quad 50.4$

1.47)

\section{Sexual orientation}

Gay

Bisexual

$\begin{array}{ccc}873 & 74.0 & 1 \\ 76 & 67.3 & 0.72 \\ & & (0.48- \\ & & 1.09)\end{array}$

\section{$604 \quad 51.2$}

$(1.02-2.67$

$10 \quad 13.3$

0.98
$(0.50-$

$4 \quad 5.3$

0.64

$(0.23-$

1.95) 1.78)

Straight

$\begin{array}{llllll}8 & 47.1 & 0.31 & 5 & 29.4 & 0.40\end{array}$

$$
\begin{array}{rr}
0.12-0.82) \quad(0.14- \\
& 1.14)
\end{array}
$$

$\begin{array}{cccccc}161 & 13.6 & 1 & 90 & 7.6 & 1 \\ 15 & 13.3 & 0.97 & 13 & 11.5 & 1.57 \\ & & (0.55- & & & (0.85- \\ & & 1.71) & & & 2.92) \\ 0 & 0 & - & 1 & 5.9 & 0.76 \\ & & & & & (0.10- \\ & & & & & 5.77)\end{array}$

Age

16-25 years

$\begin{array}{rccrcc}299 & 79.1 & 1 & 198 & 52.4 & 1 \\ 655 & 70.7 & 0.64 & 469 & 50.6 & 0.93 \\ & (0.48-0.85) & & & (0.73- \\ & & & & 1.19)\end{array}$

$\begin{array}{lll}65 & 17.2\end{array}$

$26+$ years

$111 \quad 12$

0.66 (0.47-0.92)

$\begin{array}{ll}38 & 10.1\end{array}$

1

Area of residence

Glasgow

Edinburgh

$\begin{array}{ll}400 & 74.3 \\ 341 & 75.9\end{array}$

Rest of Scotland

Rest of UK

\section{Overseas}

Ethnicity

White (UK, Irish or other)

Minority ethnic group*

\section{Qualifications}

Secondary

Further/vocational

Degree/post-graduate

$\begin{array}{ccccccccc}280 & 52.0 & 1 & 85 & 15.8 & 1 & 47 & 8.7 & 1 \\ 238 & 53.0 & 1.04 & 60 & 13.4 & 0.82 & 37 & 8.2 & 0.94 \\ & & (0.81- & & & (0.58- & & & (0.60- \\ & & 1.34) & & & 1.18) & & & 1.47) \\ 104 & 51.0 & 0.96 & 20 & 9.8 & 0.58 & 10 & 4.9 & 0.54 \\ & & (0.69- & & & (0.35-0.97) & & & (0.27- \\ & & 1.32) & & & & & & 1.09) \\ 28 & 41.8 & 0.66 & 6 & 9.0 & 0.52 & 7 & 10.4 & 1.22 \\ & & (0.40- & & & (0.22- & & & (0.53- \\ & & 1.11) & & & 1.25) & & & 2.82) \\ 12 & 44.4 & 0.74 & 2 & 7.4 & 0.43 & 1 & 3.7 & 0.40 \\ & & (0.34- & & & (0.10- & & & (0.05- \\ & & 1.60) & & & 1.83) & & & 3.03)\end{array}$
$933 \quad 73.3$
$29 \quad 65.9$
0.70
1.33)

$\begin{array}{lll}639 & 50.2 \quad 1\end{array}$

$168 \quad 13$

1

$\begin{array}{llc}33 & 75.0 & 2.97 \\ & & (1.49-5.93)\end{array}$

$9 \quad 20.5$

1.69

(0.80-

$101 \quad 7.9$

$\begin{array}{ll}3 & 6.8\end{array}$

3.58)

0.85

2.79)

$\begin{array}{cccccccccccc}146 & 74.9 & 1 & 85 & 43.6 & 1 & 24 & 12.3 & 1 & 17 & 8.7 & 1 \\ 337 & 73.3 & 0.92 & 243 & 52.8 & 1.45 & 63 & 13.7 & 1.13 & 30 & 6.5 & 0.73 \\ & & (0.63- & & & (1.03-2.03) & & & (0.68- & & & (0.39- \\ & & 1.35) & & & & & & 1.87) & & & 1.36) \\ 420 & 73.6 & 0.93 & 306 & 53.6 & 1.49 & 78 & 13.7 & 1.13 & 42 & 7.4 & 0.83 \\ & & (0.64- & & & (1.08-2.07) & & & (0.69- & & & (0.46- \\ & & 1.36) & & & & & & 1.84) & & & 1.50)\end{array}$


Table 3 Factors associated with contact with HIV prevention activities in the past 12 months $(\mathbf{N}=1318)$ (Continued)

Frequency of gay scene use

Once month or less

2/3 times a month

1/2 times a week

4/5 times a week

HIV treatment optimism $1 \dagger$

Disagree

Agree

HIV treatment optimism 2

Disagree

Agree

\section{Sexual Health}

HIV test in the past 12 months

No

Yes

Other STI test in the past 12 months

No

Yes

HIV status (oral fluid specimen result) HIV-negative

HIV-positive

Did not provide oral fluid specimen

\section{Sexual Risk Behaviours in past 12 months}

Number of sexual partners

Less than 10

10 or more

Number of anal intercourse partners

Less than 10

10 or more

Number of unprotected anal intercourse (UAI) partners

0/1 partner

2 or more partners

UAI with casual partners

No

Yes

$\begin{array}{cccccccccccc}197 & 60.2 & 1 & 139 & 42.5 & 1 & 30 & 9.2 & 1 & 18 & 5.5 & 1 \\ 261 & 73.7 & 1.85 & 182 & 51.4 & 1.43 & 36 & 10.2 & 1.12 & 24 & 6.8 & 1.25 \\ & & (1.34-2.56) & & & (1.06-1.94) & & & (0.67- & & & (0.67- \\ & & & & & & & 1.87) & & & 2.35) \\ 338 & 78.2 & 2.37 & 245 & 56.7 & 1.77 & 62 & 14.4 & 1.66 & 30 & 6.9 & 1.28 \\ & & (1.73-3.26) & & & (1.33-2.37) & & & (1.05-2.63) & & & (0.70- \\ & & & & & & & & & & & \\ & & & & & & & & & & & \end{array}$

$\begin{array}{llllllllllll}144 & 86.2 & 4.13 & 95 & 56.9 & 1.79 & 41 & 24.6 & 3.22 & 27 & 16.2 & 3.31\end{array}$

$\begin{array}{llll}(2.52-6.76) & (1.23-2.60) & (1.93-5.39)\end{array}$

$\begin{array}{cccccccccccc}696 & 74.2 & 1 & 497 & 53.0 & 1 & 123 & 13.1 & 1 & 73 & 7.8 & 1 \\ 236 & 72.2 & 0.90 & 153 & 46.8 & 0.78 & 46 & 14.1 & 1.09 & 28 & 8.6 & 1.11 \\ & & (0.68- & & & (0.61- & & & (0.75- & & & (0.70- \\ & & 1.20) & & & 1.00) & & & 1.56) & & & 1.75)\end{array}$

$\begin{array}{cccccccccccc}778 & 73.7 & 1 & 545 & 51.6 & 1 & 138 & 13.1 & 1 & 72 & 6.8 & 1 \\ 154 & 73.7 & 1.00 & 105 & 50.2 & 0.95 & 31 & 14.8 & 1.16 & 29 & 13.9 & 2.20 \\ & & (0.71- & & & (0.70- & & & (0.76- & & & (1.39-3.49) \\ & & 1.40) & & & 1.27) & & & 1.77) & & & \end{array}$

$\begin{array}{cccccccccccc}460 & 69.0 & 1 & 296 & 44.4 & 1 & 52 & 7.8 & 1 & 23 & 3.4 & 1 \\ 486 & 78.6 & 1.66 & 366 & 59.2 & 1.82 & 121 & 19.6 & 2.88 & 79 & 12.8 & 4.10 \\ & & (1.29-2.13) & & & (1.46-2.27) & & & (2.04-4.07) & & & (2.54-6.62)\end{array}$

$\begin{array}{llllllllllll}470 & 66.1 & 1 & 313 & 44.0 & 1 & 57 & 8.0 & 1 & 32 & 4.5 & 1\end{array}$

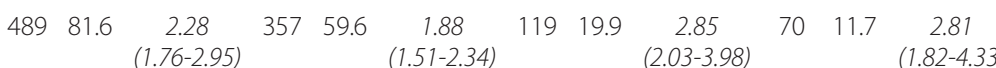

$\begin{array}{cccccccccccc}787 & 73.1 & 1 & 558 & 51.8 & 1 & 149 & 13.8 & 1 & 82 & 7.6 & 1 \\ 35 & 76.1 & 1.17 & 32 & 69.6 & 2.13 & 7 & 15.2 & 1.12 & 11 & 23.9 & 3.81 \\ & & (0.59- & & & (1.12-4.03) & & & (0.49- & & & (1.87-7.79) \\ & & 2.34) & & & & & & 2.55) & & & \\ 139 & 72.4 & 0.97 & 82 & 42.7 & 0.69 & 22 & 11.5 & 0.81 & 12 & 6.3 & 0.81 \\ & & (0.69- & & & (0.51-0.95) & & & (0.50- & & & (0.43- \\ & & 1.36) & & & & & & 1.30) & & & 1.51)\end{array}$

$\begin{array}{cccccccccccc}644 & 69.5 & 1 & 450 & 48.5 & 1 & 111 & 12.0 & 1 & 66 & 7.1 & 1 \\ 296 & 85.1 & 2.50 & 211 & 60.6 & 1.63 & 62 & 17.8 & 1.59 & 37 & 10.6 & 1.55 \\ & & (1.81-3.47) & & & (1.27-2.10) & & & (1.14-2.24) & & & (1.02-2.37)\end{array}$

$\begin{array}{cccccccccccc}813 & 72.2 & 1 & 568 & 50.4 & 1 & 139 & 12.3 & 1 & 86 & 7.6 & 1 \\ 122 & 90.4 & 3.61 & 88 & 65.2 & 1.84 & 32 & 23.7 & 2.21 & 16 & 11.9 & 1.63 \\ & & (2.01-6.50) & & & (1.27-2.67) & & & (1.43-3.41) & & & (0.92- \\ & & & & & & & & & & & \\ & & & & & & & & & & \end{array}$

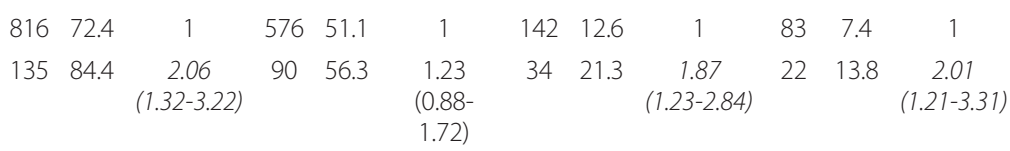

$\begin{array}{cccccccccccc}737 & 72.0 & 1 & 513 & 50.1 & 1 & 129 & 12.6 & 1 & 79 & 7.7 & 1 \\ 214 & 81.1 & 1.66 & 153 & 58.0 & 1.37 & 47 & 17.8 & 1.50 & 26 & 9.8 & 1.31 \\ & & (1.19-2.33) & & & (1.04-1.80) & & & (1.04-2.16) & & & (0.82- \\ & & & & & & & & & & & \end{array}$


Table 3 Factors associated with contact with HIV prevention activities in the past 12 months $(\mathbf{N}=1318)($ Continued)

\begin{tabular}{|c|c|c|c|c|c|c|c|c|c|c|c|c|}
\hline \multicolumn{13}{|c|}{ UAI with partners of unknown/discordant HIV status } \\
\hline No & 701 & 72.6 & 1 & 503 & 52.1 & 1 & 127 & 13.1 & 1 & 74 & 7.7 & 1 \\
\hline Yes & 250 & 77.9 & $\begin{array}{c}1.33 \\
(0.99- \\
1.80)\end{array}$ & 163 & 50.8 & $\begin{array}{c}0.95 \\
(0.74- \\
1.22)\end{array}$ & 49 & 15.3 & $\begin{array}{c}1.19 \\
(0.83- \\
1.70)\end{array}$ & 31 & 9.7 & $\begin{array}{c}1.29 \\
(0.83- \\
2.00)\end{array}$ \\
\hline \multicolumn{13}{|l|}{ STI } \\
\hline No & 870 & 72.4 & 1 & 593 & 49.3 & 1 & 148 & 12.3 & 1 & 77 & 6.4 & 1 \\
\hline Yes & 89 & 81.7 & $\begin{array}{c}1.70 \\
(1.03-2.80)\end{array}$ & 76 & 69.7 & $\begin{array}{c}2.37 \\
(1.55-3.61)\end{array}$ & 26 & 23.9 & $\begin{array}{c}2.23 \\
(1.39-3.58)\end{array}$ & 24 & 22.0 & $\begin{array}{c}4.13 \\
(2.48-6.86)\end{array}$ \\
\hline
\end{tabular}

$\mathrm{OR}=$ odds ratio; $95 \% \mathrm{Cl}=95 \%$ confidence interval; significant odds ratios are shown in italics, $\mathrm{p}<0.05$.

*Black African, Black Caribbean, Indian, Pakistani, Chinese, Arab, Latin American \& Other/Mixed.

† HIV treatment optimism 1 - 'I am less worried about HIV infection now that treatments have improved', HIV treatment optimism 2 - 'I believe that new drug therapies make people with HIV less infectious'.

services to change risk behaviour. Furthermore, our examination of associations between prevention activities and sexual risk is limited to the behaviours for which data were collected and these aggregate measures may miss more complex risk reduction strategies being employed by individual men. However, the results provide interesting insight into men's current contact with a range of HIV prevention activities available to them and the following discussion concentrates on the implications of the findings for future HIV prevention efforts.

It is encouraging that the majority of men had some contact with HIV prevention activities. Condom provision is a core component of HIV prevention [19]. Considerably more men reported obtaining free condoms than any of the other activities and it presents an opportunity for further prevention efforts and community engagement (e.g. using existing condom distribution methods to distribute other sexual health or HIV communications). Half of the men surveyed had accessed such sexual health materials, either via leaflets or online, and mass communication, or social marketing, campaigns (some of which include the provision and distribution of leaflets in addition to more general poster or media advertising) continue to be frequently employed as a means of HIV-related health promotion [20]. Indeed, the recently published Scottish HIV Action Plan includes a specific recommendation to develop and implement social marketing materials for MSM [2]. With the Internet now a recognised setting that MSM are likely to utilise to meet sexual partners [21], and evidence supporting online health promotion [22], interest has grown in using the Internet as a setting for HIV prevention interventions. However, both mass communication and Internet interventions are often difficult to evaluate and, to date, have been shown to have limited impact on risk behaviour [20,23].

Talking to outreach workers in bars, clubs or saunas, though markedly less common than obtaining free condoms or accessing sexual information via leaflets or the
Internet, appears to continue to have a role in increasing access to sexual health services, as evidenced here by the association between this and HIV/STI testing. Our previous evaluation of the Gay Men's Task Force peer education intervention reported similar findings, with higher rates of service use among men who had talked to peer educators in bars [10]. Outreach workers are ideally placed to direct at risk men to sexual health services and to support other, more general, social marketing campaigns.

Utilising one to one or group counselling on sexual health or HIV prevention, the most intensive form of prevention examined here, was also the least commonly reported. The association between testing, HIV, STIs and counselling could reflect the risk reduction counselling provided by sexual health practitioners when men present for testing or treatment. As such, these interactions represent the opportunity for interventions to effect behaviour change, as noted in existing UK guidance [24]. Intervention delivery by health care providers, and in settings where people receive routine HIV care or services, are two of the characteristics of successful interventions [25]. Sexual health services would be appropriate settings for such interventions in the UK. They would also be the most appropriate setting for the combination of these with biomedical interventions, such as early treatment for HIV to contribute to reducing community viral load, in which there is growing interest [26-29].

This is a highly sexually active sample, and at the bivariate level, contact with HIV prevention activities was consistently more common among men with more sexual partners and greater sexual risk behaviours (with the exception of UAI with partners of unknown or discordant HIV status). Although this suggested men at greater risk were making use of existing activities (which theoretically could help reduce their risk), it is striking that these associations did not remain significant in multivariate analysis (though, as noted above, frequency of gay scene use could be taken as a proxy for risk 
Table 4 Factors associated with contact with HIV prevention activities in the past 12 months: multivariate logistic regression $(\mathrm{N}=1318)$

\begin{tabular}{|c|c|c|c|c|c|c|c|c|}
\hline & \multicolumn{2}{|c|}{$\begin{array}{l}\text { Obtained free } \\
\text { condoms from a } \\
\text { bar/club/sauna or } \\
\text { the Internet }\end{array}$} & \multicolumn{2}{|c|}{$\begin{array}{l}\text { Picked up sexual } \\
\text { health leaflet in a } \\
\text { bar/club/sauna or } \\
\text { looked for safer sex/ } \\
\text { sexual health } \\
\text { information on the } \\
\text { Internet }\end{array}$} & \multicolumn{2}{|c|}{$\begin{array}{c}\text { Talked to an } \\
\text { outreach worker } \\
\text { in a bar/club/ } \\
\text { sauna }\end{array}$} & \multicolumn{2}{|c|}{$\begin{array}{l}\text { Participated in one } \\
\text { to one or group } \\
\text { counselling on } \\
\text { sexual health or } \\
\text { HIV prevention }\end{array}$} \\
\hline & AOR & $(95 \% \mathrm{Cl})$ & AOR & $(95 \% \mathrm{Cl})$ & AOR & $(95 \% \mathrm{Cl})$ & AOR & $(95 \% \mathrm{Cl})$ \\
\hline \multicolumn{9}{|l|}{ Survey venue } \\
\hline Bar & & & 1 & & & & & \\
\hline Sauna & & & 1.46 & $(0.86-2.46)$ & & & & \\
\hline \multicolumn{9}{|l|}{ Sexual orientation } \\
\hline Gay & 1 & & & & & & & \\
\hline Bisexual & 0.87 & $(0.56-1.35)$ & & & & & & \\
\hline Straight & 1.03 & $(0.28-3.74)$ & & & & & & \\
\hline \multicolumn{9}{|l|}{ Age } \\
\hline $16-25$ years & 1 & & & & 1 & & & \\
\hline $26+$ years & 0.73 & $(0.53-0.99)$ & & & 0.76 & $(0.53-1.09)$ & & \\
\hline \multicolumn{9}{|l|}{ Area of residence } \\
\hline Glasgow & 1 & & & & 1 & & & \\
\hline Edinburgh & 1.11 & $(0.81-1.51)$ & & & 0.79 & $(0.54-1.15)$ & & \\
\hline Rest of Scotland & 0.89 & $(0.61-1.30)$ & & & 0.63 & $(0.37-1.09)$ & & \\
\hline Rest of UK & 0.73 & $(0.42-1.29)$ & & & 0.63 & $(0.26-1.56)$ & & \\
\hline Overseas & 1.26 & $(0.46-3.46)$ & & & 0.43 & $(0.10-1.94)$ & & \\
\hline \multicolumn{9}{|l|}{ Ethnicity } \\
\hline White (UK, Irish or other) & & & 1 & & & & & \\
\hline Minority ethnic group* & & & 2.91 & $(1.43-5.95)$ & & & & \\
\hline \multicolumn{9}{|l|}{ Qualifications } \\
\hline Secondary & & & 1 & & & & & \\
\hline Further/vocational & & & 1.35 & $(0.95-1.93)$ & & & & \\
\hline Degree/post-graduate & & & 1.36 & $(0.96-1.93)$ & & & & \\
\hline \multicolumn{9}{|l|}{ Frequency of gay scene use } \\
\hline Once month or less & 1 & & 1 & & 1 & & 1 & \\
\hline $2 / 3$ times a month & 1.67 & $(1.19-2.35)$ & 1.34 & $(0.97-1.84)$ & 1.01 & $(0.60-1.71)$ & 1.10 & $(0.57-2.13)$ \\
\hline 1/2 times a week & 1.92 & $(1.36-2.69)$ & 1.62 & $(1.19-2.20)$ & 1.30 & $(0.80-2.11)$ & 1.01 & $(0.54-1.92)$ \\
\hline $4 / 5$ times a week & 3.13 & $(1.85-5.27)$ & 1.51 & $(1.01-2.26)$ & 2.16 & $(1.24-3.76)$ & 2.43 & $(1.23-4.82)$ \\
\hline \multicolumn{9}{|l|}{ HIV treatment optimism $2 \dagger$} \\
\hline Disagree & & & & & & & 1 & \\
\hline Agree & & & & & & & 2.19 & $(1.33-3.61)$ \\
\hline \multicolumn{9}{|l|}{ HIV test in the past 12 months } \\
\hline No & 1 & & 1 & & 1 & & 1 & \\
\hline Yes & 0.71 & $(0.49-1.03)$ & 1.30 & $(0.95-1.79)$ & 1.75 & $(1.08-2.83)$ & 3.44 & $(1.82-6.49)$ \\
\hline \multicolumn{9}{|l|}{ Other STI test in the past 12 months } \\
\hline No & 1 & & 1 & & 1 & & 1 & \\
\hline Yes & 2.44 & $(1.67-3.57)$ & 1.31 & $(0.95-1.81)$ & 1.64 & $(1.01-2.64)$ & 0.99 & $(0.54-1.80)$ \\
\hline \multicolumn{9}{|l|}{ HIV status (oral fluid specimen result) } \\
\hline HIV-negative & & & 1 & & & & 1 & \\
\hline HIV-positive & & & 1.88 & $(0.96-3.67)$ & & & 3.22 & $(1.42-7.29)$ \\
\hline Did not provide oral fluid specimen & & & 0.70 & $(0.50-0.96)$ & & & 0.82 & $(0.42-1.60)$ \\
\hline \multicolumn{9}{|l|}{ Number of sexual partners } \\
\hline Less than 10 & 1 & & 1 & & 1 & & 1 & \\
\hline 10 or more & 1.76 & $(1.19-2.62)$ & 1.16 & $(0.84-1.60)$ & 0.98 & $(0.61-1.58)$ & 0.97 & $(0.60-1.58)$ \\
\hline
\end{tabular}


Table 4 Factors associated with contact with HIV prevention activities in the past 12 months: multivariate logistic regression $(\mathrm{N}=1318)$ (Continued)

\begin{tabular}{|c|c|c|c|c|c|c|c|c|}
\hline \multicolumn{9}{|c|}{ Number of anal intercourse partners } \\
\hline Less than 10 & 1 & & 1 & & 1 & & & \\
\hline 10 or more & 1.67 & $(0.83-3.35)$ & 1.20 & $(0.75-1.91)$ & 1.56 & $(0.85-2.85)$ & & \\
\hline \multicolumn{9}{|c|}{ Number of unprotected anal intercourse (UAI) partners } \\
\hline 0/1 partner & 1 & & & & 1 & & 1 & \\
\hline 2 or more partners & 1.06 & $(0.60-1.88)$ & & & 1.18 & $(0.66-2.11)$ & 1.38 & $(0.80-2.41)$ \\
\hline \multicolumn{9}{|c|}{ UAI with casual partners } \\
\hline No & 1 & & 1 & & 1 & & & \\
\hline Yes & 1.16 & $(0.77-1.77)$ & 1.15 & $(0.86-1.55)$ & 1.10 & $(0.68-1.79)$ & & \\
\hline \multicolumn{9}{|l|}{ STI } \\
\hline No & 1 & & 1 & & 1 & & 1 & \\
\hline Yes & 0.73 & $(0.42-1.27)$ & 1.54 & $(0.98-2.44)$ & 1.35 & $(0.80-2.27)$ & 2.53 & $(1.40-4.57)$ \\
\hline
\end{tabular}

AOR = adjusted odds ratio; $95 \% \mathrm{Cl}=95 \%$ confidence interval; significant odds ratios are shown in italics, $\mathrm{p}<0.05$.

*Black African, Black Caribbean, Indian, Pakistani, Chinese, Arab, Latin American \& Other/Mixed.

† HIV treatment optimism 2 - 'I believe that new drug therapies make people with HIV less infectious'.

behaviour). Prevention efforts have been ongoing at a time when HIV-related sexual risk behaviour has essentially stabilised in this population (at a high level first observed in 2002 [13,30]). Although this plateau could be interpreted as evidence of successful prevention efforts, and stabilisation of risk behaviours during periods of intensified prevention efforts have been noted elsewhere [31,32], continued efforts are needed to address sexual risk among the minority of men for whom this appears to have become the norm [30]. Our results suggest high-risk men, those in contact with sexual health services, are accessing HIV prevention. Therefore, it is possible such prevention needs to be renewed, reinvigorated, or changed entirely, if reductions in sexual risk behaviours are to be achieved.

\section{Conclusions}

Calls for a renewed community response to HIV among MSM have been based on the early, successful HIV prevention and the widespread adoption of safer sex behaviours, which resulted from this [4]. However, recent research has highlighted the evolving nature of the gay community [5-7], questioning the likelihood and potential of a renewed community response to the HIV epidemic among MSM. Furthermore, although there is growing evidence of the potential effectiveness of individual, group and community-level behavioural HIV prevention interventions in reducing high-risk sexual behaviour among MSM [33], behaviour change alone is unlikely to achieve the sustained reductions in HIV transmission necessary to change the course of the HIV epidemic [3]. Multi-level, combination prevention could be the way forward [3], and opportunities exist to exploit men's current contact with HIV prevention activities further.
We have demonstrated that men at highest risk, and those likely to be in contact with sexual health services, are those who report most contact with current HIV prevention activities. In addition, our previous research has shown that peer outreach can increase the uptake of sexual health services [10]. If we are to offer combination prevention, a model for delivering this could therefore include outreach by peer health workers, encouraging increased uptake of sexual health services delivering behavioural and biomedical interventions, and supported by social marketing to ensure continued community engagement and support. Whilst general education to encourage condom use by MSM should continue, focused investment in the needs of those at highest risk, including those diagnosed HIV positive, may generate a prevention dividend in the long term.

\section{Additional material}

Additional file 1: Questionnaire. 2008 survey questionnaire

\section{Acknowledgements}

We thank the survey staff and fieldworkers in each city, the venue managers, their staff, and the men who agreed to participate in the survey. The UK Medical Research Council funds LMcD and the Gay Men's Survey as part of the Sexual and Reproductive Health Programme (WBS U.1300.00.005) at the Social and Public Health Sciences Unit.

\section{Author details}

'MRC/CSO Social and Public Health Sciences Unit, 4 Lilybank Gardens, Glasgow, G12 8RZ, UK. ${ }^{2}$ Centre for Sexual Health and HIV Research, Research Department of Infection and Population Health, University College London, Mortimer Market Centre, off Capper Street, London, WC1E 6JB, UK.

\section{Authors' contributions}

LMCD devised the paper, conducted the analyses and wrote the first draft. $\mathrm{GH}$ made substantial comments and contributed to subsequent drafts. Both 
authors approved the final version of the manuscript submitted for publication.

\section{Competing interests}

The authors declare that they have no competing interests.

Received: 29 June 2010 Accepted: 31 December 2010 Published: 31 December 2010

\section{References}

1. Health Protection Agency: HIV in the United Kingdom: 2009 Report. London: Health Protection Agency; 2009.

2. Scottish Government: HIV Action Plan in Scotland December 2009 March 2014. Edinburgh: Scottish Government; 2009.

3. Coates TJ, Richter L, Caceres C: Behavioural strategies to reduce HIV transmission: how to make them work better. Lancet 2008, 372:669-684.

4. Merson MH, O'Malley J, Serwadda D, Apisuk C: The history and challenge of HIV prevention. Lancet 2008, 372:475-488.

5. Davis M: The 'loss of community' and other problems for sexual citizenship in recent HIV prevention. Sociol Health IIIn 2008, 30:182-196.

6. Rowe MS, Dowsett GW: Sex, love, friendship, belonging and place: is there a role for 'gay community' in HIV prevention today? Cult Health Sex 2008, 10:329-344.

7. Rosser BRS, West W, Weinmeyer R: Are gay communities dying or just in transition? Results from an international consultation examining possible structural change in gay communities. AIDS Care 2008, 20:588-595.

8. Wohlfeiler D: From community to clients: the professionalisation of HIV prevention among gay men and its implications for intervention selection. Sex Transm Infect 2002, 78(Suppl 1):i176-i182.

9. Hart G, Flowers P, Der G, Frankis J: Homosexual men's HIV-related sexual risk behaviour in Scotland. Sex Transm Infect 1999, 75:242-246.

10. Williamson L, Hart G, Flowers P, Frankis J, Der G: The Gay Men's Task Force: the impact of peer education on the sexual health behaviour of gay men in Glasgow. Sex Transm Infect 2001, 77:427-432.

11. Flowers P, Hart GJ, Williamson LM, Frankis JS, Der GJ: Does bar-based, peer-led sexual health promotion have a community-level effect amongst gay men in Scotland? Int J STD AIDS 2002, 13:102-108.

12. Hart GJ, Williamson LM, Flowers P, Frankis JS, Der GJ: Gay men's HIV testing behaviour in Scotland. AIDS Care 2002, 14:665-674.

13. Hart GJ, Williamson LM: Increase in HIV sexual risk behaviour in gay men in Scotland, 1996-2002: Prevention failure? Sex Transm Infect 2005, 81:367-372.

14. Williamson LM, Dodds JP, Mercey DE, Johnson AM, Hart GJ: Increases in HIV-related sexual risk behaviour among community samples of gay men in London and Glasgow: how do they compare? J Acquir Immune Defic Syndr 2006, 42:238-241.

15. Williamson LM, Hart GJ: HIV prevalence and undiagnosed infection among a community sample of gay men in Scotland. J Acquir Immune Defic Syndr 2007, 45:224-230.

16. Williamson LM, Dodds J, Mercey DE, Hart GJ, Johnson AM: Sexual risk behaviour and knowledge of HIV status among community samples of gay men in the UK. AIDS 2008, 22:1063-1070.

17. Williamson LM, Flowers P, Knussen C, Hart GJ: HIV testing trends among gay men in Scotland, UK (1996-2005): implications for HIV testing policies and prevention. Sex Transm Infect 2009, 85:550-554.

18. Sanchez T, Finlayson T, Drake A, Behel S, Cribbin M, DiNenno E, Hall T, Kramer S, Lansky A: Human immunodeficiency virus (HIV) risk, prevention, and testing behaviours - United States, National HIV Behavioural Surveillance System: Men who have sex with men November 2003-April 2005. MMWR Surveillance Summaries 2006, 55(SS06): :-16.

19. Feldblum PJ, Welsh MJ, Steiner MJ: Don't overlook condoms for HIV prevention. Sex Transm Infect 2003, 79:268-269.

20. Noar SM, Palmgreen P, Chabot M, Dobransky N, Zimmerman RS: A 10-year systematic review of HIV/AIDS mass communication campaigns: Have we made progress? J Health Commun 2009, 14:15-42.

21. Liau A, Millett G, Marks $G$ : Meta-analytic examination of online sexseeking and sexual risk behaviour among men who have sex with men. Sex Transm Dis 2006, 33:576-584.
22. Bolding G, Davis $M$, Sherr $L$, Hart $G$, Elford J: Use of gay Internet sites and views about online health promotion among men who have sex with men. AIDS Care 2004, 16:993-1001.

23. Noar SM, Black HG, Pierce LB: Efficacy of computer technology-based HIV prevention interventions: a meta-analysis. AIDS 2009, 23:107-115.

24. National Institute for Health and Clinical Excellence: One to one interventions to reduce the transmission of sexually transmitted infections (STIs) including HIV, and to reduce the rate of under 18 conceptions, especially among vulnerable and at risk groups. London: National Institute for Health and Clinical Excellence; 2007.

25. Crepaz N, Lyles CM, Wolitski RJ, Passin WF, Rama SM, Herbst JH, Purcell DW, Malow RM, Stall R, HIV/AIDS Prevention Research Synthesis Team: Do prevention interventions reduce HIV risk behaviours among people living with HIV? A meta-analytic review of controlled trials. AIDS 2006, 20:143-157,

26. Montaner JSG, Hogg R, Wood E, Kerr T, Tyndall M, Levy AA, Harrigan PR: The case for expanding access to highly active antiretroviral therapy to curb the growth of the HIV epidemic. Lancet 2006, 368:531-536.

27. Wagner BG, Kahn JS, Blower S: Should we try to eliminate HIV epidemics by using a 'Test and Treat' strategy? AIDS 2010, 24:775-776.

28. Granich RM, Gilks CF, Dye C, De Cock KM, Williams BG: Universal voluntary HIV testing with immediate antiretroviral therapy as a strategy for elimination of HIV transmission: a mathematical model. Lancet 2009, 373:48-57.

29. Dodd PJ, Garnett GP, Hallett TB: Examining the promise of HIV elimination by 'test and treat' in hyperendemic settings. AIDS 2010, 24:729-735.

30. Knussen C, Flowers P, McDaid LM, Hart GJ: Age-related trends in HIVrelated sexual risk behaviour in Scotland among men who have sex with men: 1996-2008. Sex Transm Infect .

31. Elford J, Bolding G, Sherr L, Hart G: High-risk sexual behaviour among London gay men: no longer increasing. AIDS 2005, 19:2171-2174.

32. Lattimore S, Thornton A, Delpech V, Elford J: Trends in sexual risk behaviour among London gay men between 1998 and 2008 [abstract no. OS1.2.04]. 18th International Society for STD Research Conference 2009; London, UK

33. Johnson WD, Diaz RM, Flanders WD, Goodman M, Hill AN, Holtgrave D, Malow R, McClellan WM: Behavioural interventions to reduce risk for sexual transmission of HIV among men who have sex with men. Cochrane Database Syst Rev 2008, , 3: CD001230.

\section{Pre-publication history}

The pre-publication history for this paper can be accessed here: http://www.biomedcentral.com/1471-2458/10/798/prepub

\section{doi:10.1186/1471-2458-10-798}

Cite this article as: McDaid and Hart: Contact with HIV prevention services highest in gay and bisexual men at greatest risk: crosssectional survey in Scotland. BMC Public Health 2010 10:798.

\section{Submit your next manuscript to BioMed Central and take full advantage of:}

- Convenient online submission

- Thorough peer review

- No space constraints or color figure charges

- Immediate publication on acceptance

- Inclusion in PubMed, CAS, Scopus and Google Scholar

- Research which is freely available for redistribution

Submit your manuscript at www.biomedcentral.com/submit
C Biomed Central 